\title{
A review of new evaluation models for strategic communication: Progress and gaps
}

\author{
Jim Macnamara \\ University of Technology Sydney
}

\begin{abstract}
After identification of "stasis" in evaluation of strategic communication including public relations and corporate communication despite intensive focus for more than 40 years, recent initiatives in measurement and evaluation on three continents highlight a number of important advances in theory and practice. While studies have identified a lack of standards and a narrow focus on 'activities' and 'outputs' in traditional evaluation models and literature, a two-year international study, which examined a number of recently-developed evaluation frameworks and models and accompanying implementation guidelines, identifies several new concepts and dimensions in evaluation, along with some remaining gaps for further research. Based on content analysis of evaluation literature, interviews, and ethnography, this article reports four key findings of recent research and explains how these can contribute to theory-building and practice to transform the planning, implementation, and evaluation of public relations and corporate, government, organizational and marketing communication.
\end{abstract}

Keywords: Measurement, evaluation, strategy, public relations, communication

\section{'Stasis' and 'reinventing the wheel' in evaluation}

Evaluation of professional public communication practices has been described as being in a state of 'stasis' for some time (Gregory \& Watson, 2008; Macnamara \& Zerfass, 2017), or what also has been described as a "deadlock" (Macnamara, 2015). Studies have shown a narrow focus on measuring outputs such as media publicity, advertising reach, social media posts, and Web site and video views, rather than outcomes or impact (Macnamara \& Zerfass, 2017; Zerfass, Verčič, Verhoeven, Moreno, \& Tench, 2012). Furthermore, historical analysis of strategic communication evaluation has shown that practices such as public relations (PR) have gone down a path of 'reinventing the wheel' by frequent introduction of new measures and methods rather than adopting widely-used evaluation models and methods based on theory of change and program theory (Macnamara \& Likely, 2017) ${ }^{1}$. Despite extensive literature on evaluation in fields such as international development, public administration, and education, and adoption of program theory (Bickman, 1990; Funnell \& Rogers, 2011) and program logic models for evaluation, which identify stages as inputs, activities, outputs, outcomes, and impact (Henert \& Taylor-Power, 2008; Kellogg Foundation (1998/2004; (Knowlton \& Phillips, 2013), public relations and related areas of strategic communication have created new terms such as 'outgrowths', 'outflows' and 'outtakes' and made up metrics such as advertising value equivalents (AVEs).

Even though researchers have identified a concerted focus on measurement and evaluation of public relations and corporate communication since the late 1970s (Likely and Watson, 2013; Watson, 2012; Watson \& Noble, 2014), the 2015 European Communication Monitor, a survey of more than 2,000 communication professionals across 41 European countries, has reported that more than 80 per cent still rely on counting the volume of publicity as their main method 
of evaluation (Zerfass, Verčič, Verhoeven, Moreno \& Tench, 2015, p. 72). Also, recent studies have shown that up to one-third of practitioners continue to use invalid metrics such as AVEs (USC \& The Holmes Report, 2016) along with "vanity metrics” (Bartholomew, 2016, p. 97), such as high volumes of internet clicks or Facebook likes, as indications of communication effectiveness.

It is ironic that a large section of the public relations industry seeks to compare itself to advertising when studies show that advertising has long been criticized for its reliance on 'reach' and 'recall' rather than evidence of outcomes or impact of communication on target audiences (Macnamara, 2018). Despite more than US\$500 billion a year being spent on advertising (e-Marketer, 2016), independent marketing researcher and analyst Jerry Thomas says that "the advertising industry, as a whole, has the poorest quality-assurance systems and turns out the most inconsistent product . . . of any industry in the world" (2008, para. 1). Furthermore, studies show that the PESO model of media use (paid, earned, shared, and owned), which has traditionally been dominated by paid media advertising, is increasingly shifting with increased use of shared and owned media and a relative decline in paid advertising (Macnamara, Lwin, Adi, \& Zerfass, 2016). The public relations industry is thus short-sighted and misguided in seeking to compare its work to advertising.

Despite the growing importance of social media and opportunities for analysis of audience response and advanced techniques such as influencer mapping using social network analysis (SNA), evaluation of online communication is often focussed on relatively meaningless metrics, as observed by Don Bartholomew (2016, p. 97). As online content marketer Sujan Patel wrote in Forbes magazine:

The number of social media followers your social profiles have attracted is one of the most vain of all the vanity metrics you can attract, yet it often consumes far too much of the company's attention. Repeat after me - just because someone follows you does not mean they're engaged with your brand. (Patel, 2015, para. 9)

Scholars and practitioners recognize evaluation as a major challenge and since 2010 a number of initiatives have been launched in an attempt to develop standards and best practice including adoption and promulgation of The Barcelona Principles ${ }^{2}$ (AMEC, 2010, 2015) and establishment of the Coalition for Public Relations Research Standards in 2011 and the Social Media Measurement Standards Conclave in 2012. These initiatives have involved a range of professional organizations including the International Association for Measurement and Evaluation of Communication (AMEC); the Institute for Public Relations (IPR); the Council of Public Relations Firms (CPRF); the Global Alliance for Public Relations and Communications Management; the International Association of Business Communicators (IABC); the Public Relations Society of America (PRSA); the UK Chartered Institute of Public Relations (CIPR); the Society for New Communications Research (SNCR); the Federation Internationale des Bureaux d'Extraits de Presse (FIBEP); the Word of Mouth Marketing Association (WOMMA); and the Digital Analytics Association (DAA). As well, these organizations consulted with the Media Ratings Council (MRC); the Interactive Advertising Bureau (IAB); the American Association of Advertising Agencies (AAAA); the Association of National Advertisers (ANA); and the Web Analytics Association.

More recently, an international Task Force on Standardization of Communication Planning and Evaluation Models has been established under the auspices of the IPR Measurement Commission and has attempted to identify or define standards, particularly for evaluation of PR. AMEC offers an online training program in evaluation and conducts annual awards to identify and promote best practice in evaluation. 
However, despite these efforts, the annual European Communication Monitor (e.g., Zerfass, Verčič, Verhoeven, Moreno, \& Tench, 2015; Tench, Verčič, Zerfass, Moreno, \& Verhoeven, 2017), the 2016 Global Communication Report (USC \& The Holmes Report, 2016), and a number of other industry studies show that evaluation remains a major challenge for strategic communication practitioners. In particular, studies show a failure "to prove the impact of communication activities on organizational goals” (Zerfass et al., 2012, p. 36; Zerfass \& Volk, 2017).

The history and poor record of evaluation of strategic communication has been widely discussed and does not need detailed analysis here. For a review of developments over the past 40 years or so, see Likely and Watson (2013), Macnamara (2018), or Watson and Noble (2014). What is most needed in an environment of stasis is identification of ways forward. The following reports the findings of a two-year study of evaluation methods conducted on three continents across a number of fields of strategic communication practice including public relations and corporate communication as well as advertising and specialist fields such as health communication.

\section{Research questions}

The research questions explored in this study were:

RQ1: What are the latest and most advanced models and methods for evaluation of strategic communication, including advertising, public relations, corporate, government, and marketing communication, and specialist fields such as health communication?

RQ2: To what extent do evaluation models for strategic communication align with evaluation theory?

RQ3: To what extent have standards been developed and adopted for evaluation of strategic communication?

RQ4: How should evaluation of strategic communication be further developed to comply with evaluation theory and best practice?

\section{Methodology}

This analysis is based on an extensive review of extant literature and empirical research undertaken on three continents (Australia, Europe, and North America) over a period of almost two years from late-2015 to mid-2017 using two qualitative methodological approaches: ethnography and participatory action research (PAR). Within these approaches three qualitative research methods were used, namely observation/participation, interviews, and content analysis of documents, along with related techniques such as journaling, as explained in the following.

\section{Ethnography}

As Stanley Geertz (1973) notes, ethnography is a qualitative research method conducted to learn and understand cultural phenomena that reflect the knowledge and system of meanings guiding the life of a cultural group. In particular, Geertz described ethnography as thick description, meaning such analysis is based on detailed observation and interpretation during an extended period of fieldwork - not simply casual observation over a short period. Barbara 
Tedlock notes that ethnographers ideally 'live in' the studied group or field for an extended period of time (2008, p. 151) and gain first-hand observation, or even participation. Geertz (1973) similarly identified the primary research methods used in ethnography as participant observation and sometimes participation by the researcher. To bring rigour to the process, ethnographic information is collected in field notes, recordings, diaries, and other data sources such as minutes of meetings, letters, reports, papers, and speeches. Also, ethnography typically includes interviews with those observed and fellow participants. All of these methods of data collection were used in this study and content analysis was undertaken of notes and transcripts of interviews.

First-hand observation and active participation was undertaken in a number of significant initiatives by organizations involved in attempting to develop standards and best practice models for evaluation of public communication during the period of the study. The key organizations and initiatives studied included:

1. The International Association for Measurement and Evaluation of Communication (AMEC) based in London during in the development of the AMEC Integrated Evaluation Framework (AMEC, 2017). The author was directly involved in this project during 2016 and early 2017;

2. The Evaluation Council of the UK Government Communication Service (GCS) in the UK Cabinet Office, Whitehall, which has established various frameworks, methods, and tools for UK government communication to be applied by all departments and agencies. During late 2015 the author participated as an external adviser in the development of the 2016 GCS Evaluation Framework (GCS, 2016) and served as a member of the GCS Evaluation Council during the period June-December 2016, which provided access to review a wide range of UK Government communication campaigns and activities;

3. The Task Force on Standardization of Communication Planning and Evaluation Models, an international collaboration of academics and public communication practitioners established in the USA in 2015 to explore standards for evaluation of public relations and communication. The author was a member of the task force throughout the period of research (2015-2017);

4. The Directorate-General for Communication (DG COM) of the European Commission (EC), which provides a framework, guidelines and a code of conduct for evaluation across European Union (EU) institutions and conducts evaluation of EC communication activities. DG COM evaluation approaches and methods were examined, discussed, and compared with international practices in a number of meetings with senior management and workshops with European Commission communication practitioners in 2016;

5. The Department of Premier and Cabinet of the New South Wales state government in Australia. From December 2015 to mid-2017 the author was involved in designing and implementing a framework and methodology for evaluating the state's AUD\$100 million (US\$75 million) a year investment in advertising and other forms of public communication;

6. The Institute of Practitioners in Advertising (IPA), the longest established advertising industry body in the world, which celebrated its centenary in 2017 and is described as "the world's most influential professional body for practitioners in advertising and marketing communications" (IPA, 2016, para. 2), was consulted and winners of the IPA's annual Effectiveness Awards along with winners of AMEC's Global Effectiveness Awards in 2016 were reviewed to identify best practice evaluation models and methods applied. 


\section{Participatory action research (PAR)}

Action research, a qualitative method developed originally from the work of Kurt Lewin (1946) to explore specific issues and/or attempt to resolve specific problems in situ during the action or actions that are the subject of study (see also Greenwood \& Levin, 2006), was adopted as a second method of primary research because, as noted previously, a number of the evaluation models examined were in development during the period of research. The author was invited to be an active participant working with teams in evaluation initiatives by AMEC, the UK GCS and its Evaluation Council, the Task Force on Standardization of Communication Planning and Evaluation Models, and a number of others. In this sense, PAR and ethnography overlap, blend, and build on each other as methods of discovery.

In particular, this study used participatory action research (Kindon, Pain, \& Kesby, 2007), an application of action research that is based on collaborative inquiry by researchers and those responsible for what is studied. While action research and PAR are criticized by some scholars for their close association with applied research, PAR in particular offers significant benefits including (1) it takes advantage of the local knowledge of those involved in the problem being investigated; (2) it gains deep understandings that are not available to 'outside' researchers 'looking in'; and (3) it gains 'buy in' and commitment from those involved to concretely address the research questions and find solutions to problems. A rigorous social research approach is maintained through deploying systematic research methods to capture and analyse data, and applying critical analysis, critical self-inquiry, and reflection.

Specific methods used in PAR include journaling by participants, a method derived from anthropology that involves writing observations and perceptions into a journal on a weekly or even daily basis; regular discussions such as meetings and forums, interviewing of key participants and stakeholders (often multiple times at various stages), and content analysis of research notes and interview transcripts to identify consensus or majority views. In this study, research notes from journaling and meetings, documents developed as part of the initiatives studied, and e-mail communication were analysed.

By invitation PAR was conducted in the Cabinet Office, Whitehall, and in the communication division of the UK Department of Health ${ }^{3}$, which included working closely with other divisions such as policy and with several of the department's arm's length bodies that agreed to participate. These included NHS England, the national body in the National Health Service of the UK responsible for commissioning and administering health care service providers such as medical practices and hospitals across the UK, and Public Health England (PHE), the agency responsible for conducting health related public communication campaigns. The UK Department of Health and its agencies spend in excess of $£ 75$ million a year on public communication campaigns excluding staff costs addressing a wide range of audiences on important issues such as obesity and healthy ageing, as well as persuasive campaigns to solicit blood and organ donations and change behaviours as part of preventative health care.

\section{Sample}

The organizations involved in ethnography and participatory action research comprised a purposive sample selected on the basis of being sites of major contemporary initiatives in the development and/or implementation of best practice evaluation of public communication. They were identified based on their publication of evaluation guidelines, standards, or models in the preceding 12 months. Also, participants in ethnographic and participatory action research were, by necessity, selected on the basis of their willingness to participate in this research. However, as no organizations refused to participate, the sample avoided bias associated with a convenience sample. 
While some of the sites of PAR were public sector organizations, there is no evidence to indicate that the findings cannot apply in private sector organizations such as corporations and in non-profit organizations. Private, public, and third sector organizations all face increasing requirements for accountability today, and initiatives to promote professionalism among communication practitioners in advertising, PR, and related fields include a focus on standards and effectiveness.

\section{Major contemporary evaluation models for strategic communication}

Three widely-used contemporary models of evaluation of strategic communication were identified and examined in this study based on review of literature in the field, along with three emergent models that were developed or were in development during the period of this research and in which the author was involved as an observer or participant, or both, as explained under 'Methodology'. The first three reflect widespread contemporary practice, while the second three reflect thinking about future directions in evaluation of strategic communication. Collectively, these six models provide insights in relation to RQ 1.

Analysis of these six models (sometimes referred to as frameworks) reveals progress, but also a number of continuing gaps in evaluation theory and practice and identifies conceptual and processual changes needed to overcome the 'stasis' in evaluation practice. Also, because these models identify the purpose and underlying logic of strategic communication, this analysis also contributes more broadly to strategic communication theory, as will be explained.

\section{The EC DG COM model}

A model that is widely used in Europe, particularly in communication campaigns conducted across the 27 countries in continental Europe that are members of the European Union (EU), is that developed by the European Commission Directorate-General for Communication (DG COM) in conjunction with its Better Regulation Guidelines (European Commission, 2015a), its Toolkit for the Evaluation of Communication Activities (European Commission, 2015b), and its External Communication Network Code of Conduct on Measurement and Evaluation of Communication Activities (European Commission, 2015c). The EC DG COM administered an external communication budget of $€ 378$ million in 2015 (US\$422 million) (European Commission, 2015d).

While the European Commission (EC) evaluation model broadly incorporates a program logic model approach, it deviates in two key respects. Figure 1 shows that the EC model suggests that communication begins with 'activities' such as organizing events and distributing information. This overlooks the important 'inputs' stage of planning during which formative evaluation is recommended to identify audience awareness, perceptions, attitudes, needs, interests, and channel preferences. Thus, this model is contrary to evaluation theory (RQ 2), which identifies three stages of evaluation: formative (also referred to as ex-ante), process, and summative (also referred to as ex-post) (Bauman \& Nutbeam, 2014). Without formative evaluation, communication proceeds without audience insights and often without baseline data for later comparison, which makes summative evaluation difficult if not impossible. Second, this model shows the second stage in the process of strategic communication as 'relevance'. The suggestion that the relevance of communication to audiences and/or to the organization should be determined after activities have been implemented is clearly flawed. Relevance is one of the key elements of SMART objectives and should be determined as part of setting communication objectives before activities are conducted and even before inputs are collected and assembled. 
Another interesting feature of the EC model is that, while communication objectives are derived (i.e., come down) from the organization, all results at output, outtake and outcome stages are conceptualized as flowing 'upwards' to the organization, as shown by the arrows in Figure 1. This characteristic and its implications will be further discussed later.

Figure 1. Evaluation model developed and used by the European Commission Directorate-General for Communication (European Commission, 2015c)

\section{0 political priorities}

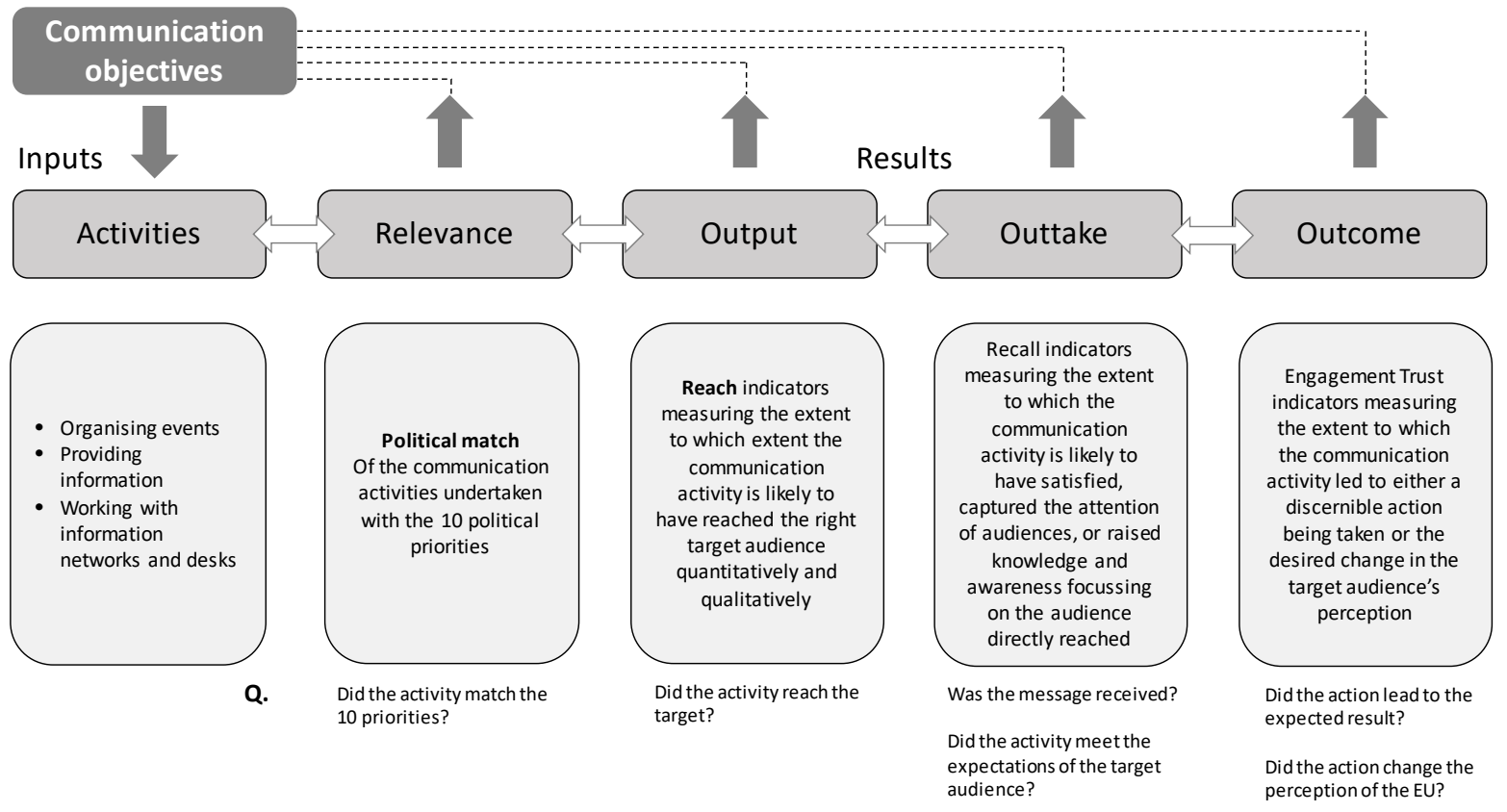

\section{The UK GCS evaluation framework}

The second contemporary evaluation model examined and discussed with the creators was the UK Government Communication Service (GCS) Evaluation Framework (GCS, 2015). This was developed in late 2015 and has been implemented since early 2016 for evaluating UK government strategic communication in which more than $£ 300$ million a year is invested. The framework includes a program logic model (see Figure 2) supported by an evaluation guide (a small booklet). To implement the framework, the GCS has implemented an intensive professional development program that produces 'Evaluation Champions' among GCS staff working across the civil service. In addition, the GCS has established an Evaluation Council made up of senior GCS staff as well as external experts such as social researchers and academics, which reviews proposed communication campaigns before implementation. The GCS initiatives are regarded as world-leading in the field of strategic communication evaluation - for instance, in 2017 the EC DG COM commissioned workshops to discuss emulating GCS approaches.

The GCS evaluation model follows evaluation program theory and program logic models more closely than does the EC model (RQ 2) by including 'inputs' as the first stage and noting that this should include formative evaluation such as "pre-testing" (see Figure 2). The GCS evaluation model also emphasizes the use of qualitative as well as quantitative research. 


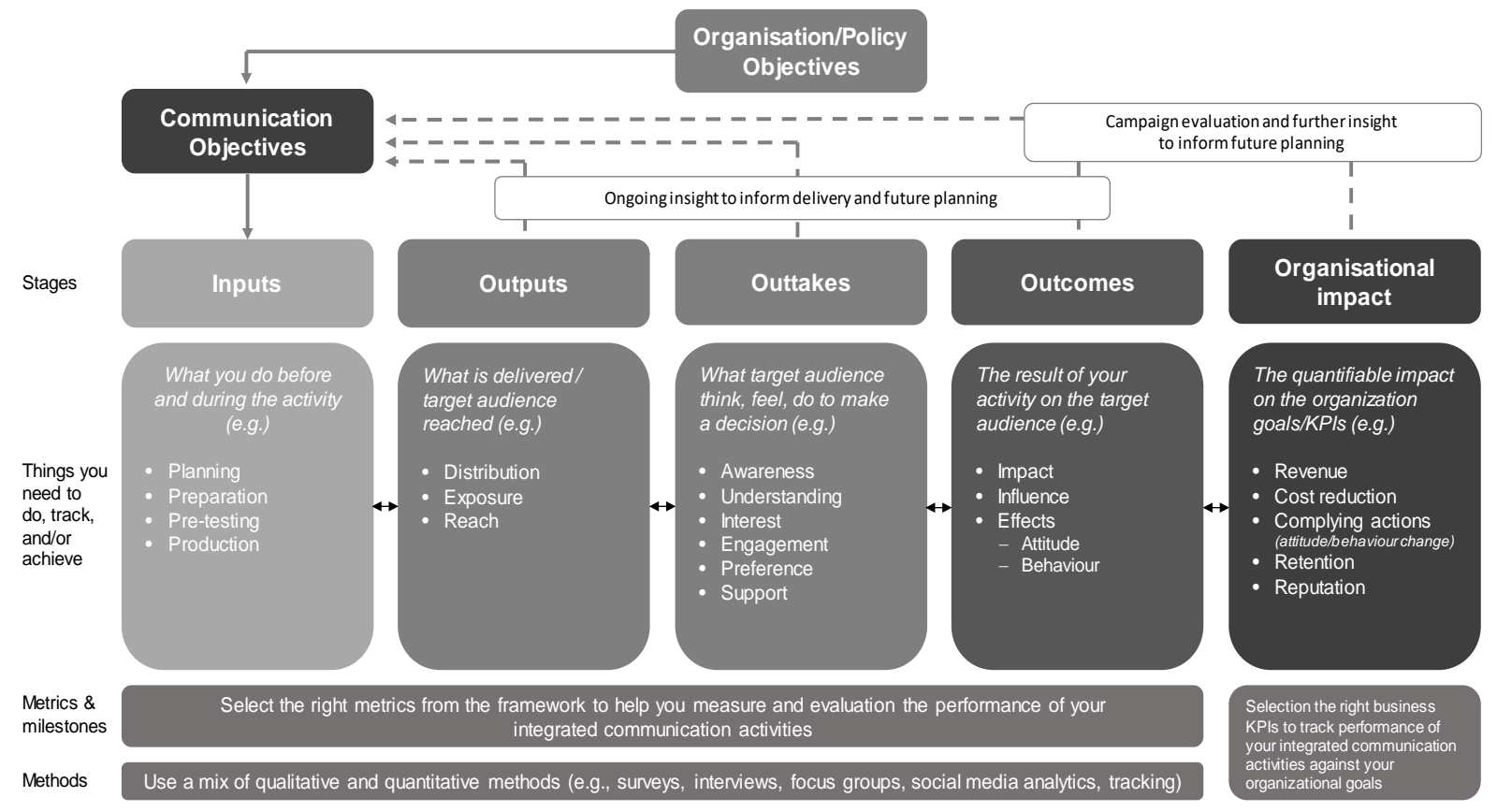

However, despite involving the external expertise of social researchers and academics, the GCS evaluation model maintains several features of earlier public relations evaluation models that deserve critical analysis and further consideration by the creators. One is the inclusion of 'outtakes' as a stage before 'outcomes'. This is not a significant variation, as 'outtakes' - a term created by Michael Fairchild (1997) in early UK Institute of Public Relations (IPR) models and later adopted by Walter Lindenmann (1997/2003) in the US - equate to short-term outcomes as described by Henert and Taylor-Power (2008). Of more significance is that, like the EC model, communication objectives as conceived as being derived from the organization and all results of communication including the final stage of impact is seen as flowing to the organization. Neither this widely-used model nor the EC model include stakeholders, publics, or society at any point in the process of evaluating public communication. This seems to be a serious omission in a model designed to guide the strategic communication of government in a democracy.

\section{The AMEC integrated evaluation framework}

In 2016 AMEC launched its Integrated Evaluation Framework (IEF) to replace the former AMEC Valid Metrics Framework. After a period of international consultation, this was upgraded to the AMEC Integrated Evaluation Framework 2.0 in May 2017 (AMEC, 2017). The AMEC IEF represents a significant breakthrough in several respects. The first noteworthy feature is that the IEF is an online application, not a static model that simply illustrates processes. Users can enter data such as their communication objectives and then progressively add data related to inputs (e.g., formative research findings such as baseline awareness or compliance rates, pre-test results, etc.), followed by data describing activities, outputs, outcomes, and finally impact. Data entry is aided by 'pop-up' information tabs at each stage, which provide users with tips of what types of data are relevant to that stage. Multiple evaluation reports can be created, saved, and produced as PDF files and printed if required. The framework (application) is also supported by a taxonomy of evaluation that provides definitions of each stage, examples of what can be expected to occur at each stage, and a list of relevant metrics and appropriate methods for generating those metrics. Thus, the AMEC IEF 
is a major advance in tools for evaluation of strategic communication, providing both a model and guidelines based on standards (RQ 3).

Figure 3. The AMEC Integrated Evaluation Framework 2.0 (AMEC, 2017).

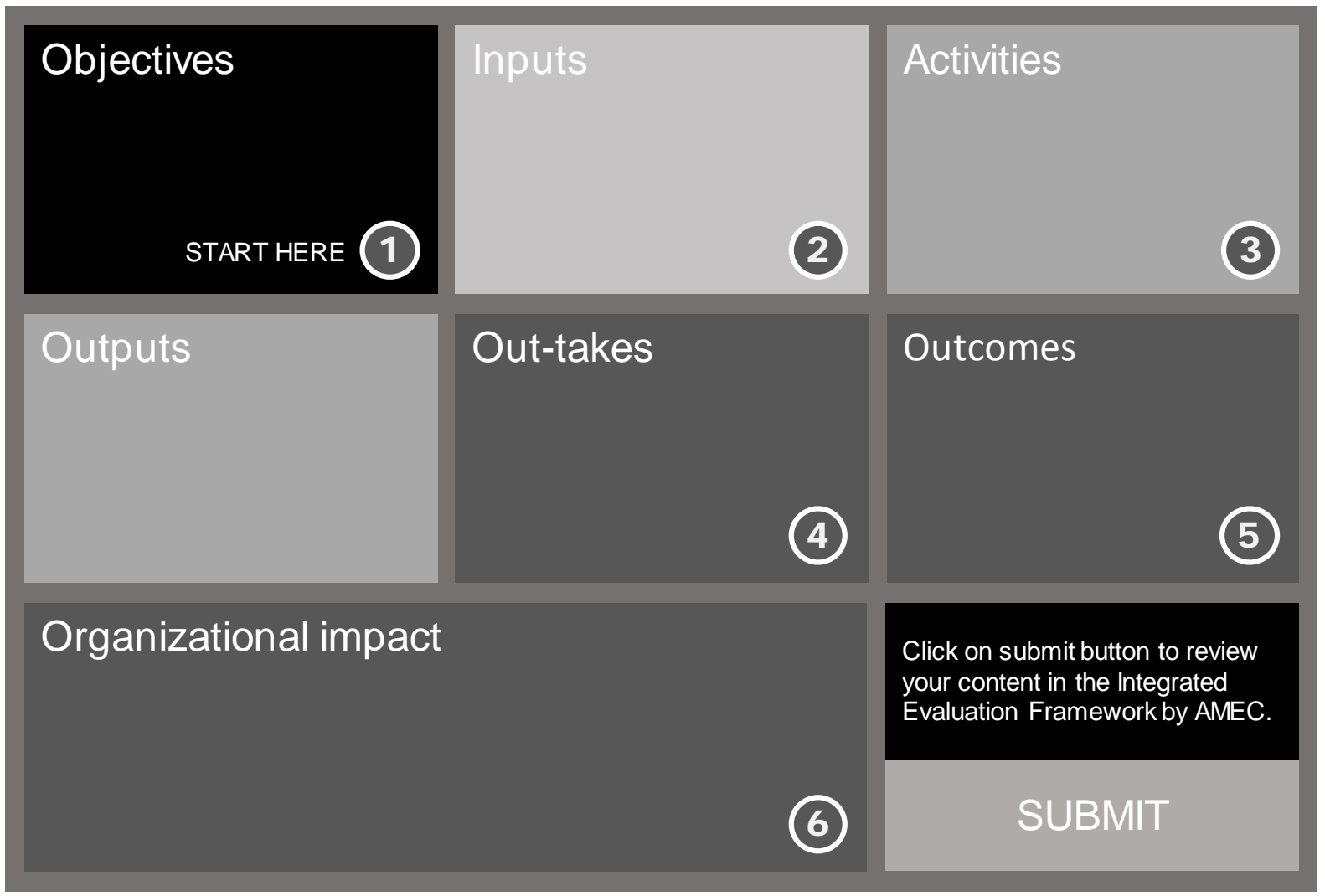

The AMEC IEF differs from other evaluation models for strategic communication and classic program logic models in that it reports in six stages including 'outtakes' as well as 'outcomes' (see Figure 3). As with the GCS model, 'outtakes' can be regarded as synonymous with shortterm outcomes in classic program logic models such as the UWEX model (Henert \& TaylorPower, 2008) and 'outcomes' interpreted as long-term outcomes.

However, one of the major failings in evaluation of strategic communication has been what Glen Broom calls the "substitution problem" (2009, p. 358) - the use of measures from one level as alleged measures at a higher level. An example is reporting volume of publicity (an 'output') as an alleged 'outcome'. Emeritus Professor of PR, Jim Grunig also has identified this problem pointing out that many practitioners use "a metric gathered at one level of analysis to show an outcome at a higher level of analysis” (2008, p. 89). It is likely that separating 'outtakes' and 'outcomes' in a six-stage model will add to practitioners' confusion and exacerbate the 'substitution problem'.

Also, despite its functionality and bringing evaluation into the digital online age, the AMEC Integrated Evaluation Framework 2.0 does not include stakeholders, publics, or society at any step or stage. While these models and others such as the 'communication controlling' model (Huhn, Sass \& Storck, 2011; Zerfass, 2010) aptly recognize the need for evaluation to align outcomes and impact to organizational goals and objectives, the omission of stakeholders, publics and society from consideration is contrary to program evaluation theory (e.g., Kellogg Foundation, 1998/2004; Henert \& Taylor-Power, 2008; Wholey, Hatry, \& Newcomer, 2010) and also contrary to disciplinary best practice such as public relations Excellence theory. 
Excellence theory calls for evaluation to be conducted at (a) programme, (b) functional (e.g., department or unit), (c) organizational and (d) societal levels (L. Grunig, J. Grunig, \& Dozier, 2002, pp. 91-92).

In these repects, the AMEC IEF does not fully align with evaluation theory (RQ 2) or standards (RQ 3).

\section{The NSW Government strategic communication evaluation framework}

The first evaluation model to explicitly recognize stakeholders, publics, and society as an integral part of two-way communication, engagement, dialogue, and relationships was developed by the strategic communications branch of the New South Wales Department of Premier and Cabinet in consultation with academics in 2016-2017 for application across the state government, which spends around AUD\$100 million a year on advertising and other forms of public communication. The DPC (2017) model shown in Figure 4, which is slightly updated from its first iteration in 2016, applies a classic five-stage program logic model customized to strategic communication, thus closely following evaluation theory (RQ 2). The information shown on the model at each stage is indicative rather than prescriptive. However, it highlights that evaluation should begin at the 'inputs' stage with formative research to gain target audience insights and collect baseline data such as existing audience awareness levels, perceptions, and channel preferences. Underneath indicative activities at each stage, the model lists suggested evaluation methods such as literature review, pre-campaign surveys, focus groups or interviews, and database records analysis at the 'inputs' stage, followed by pretesting at the 'activities' stage, and other appropriate methods throughout the program. The indicative information in the model clearly demarks the difference between inputs, activities, outputs, outcomes, and impact and suggests evaluation methods that are appropriate for each.

Figure 4. The NSW Government evaluation framework (DPC, 2017).

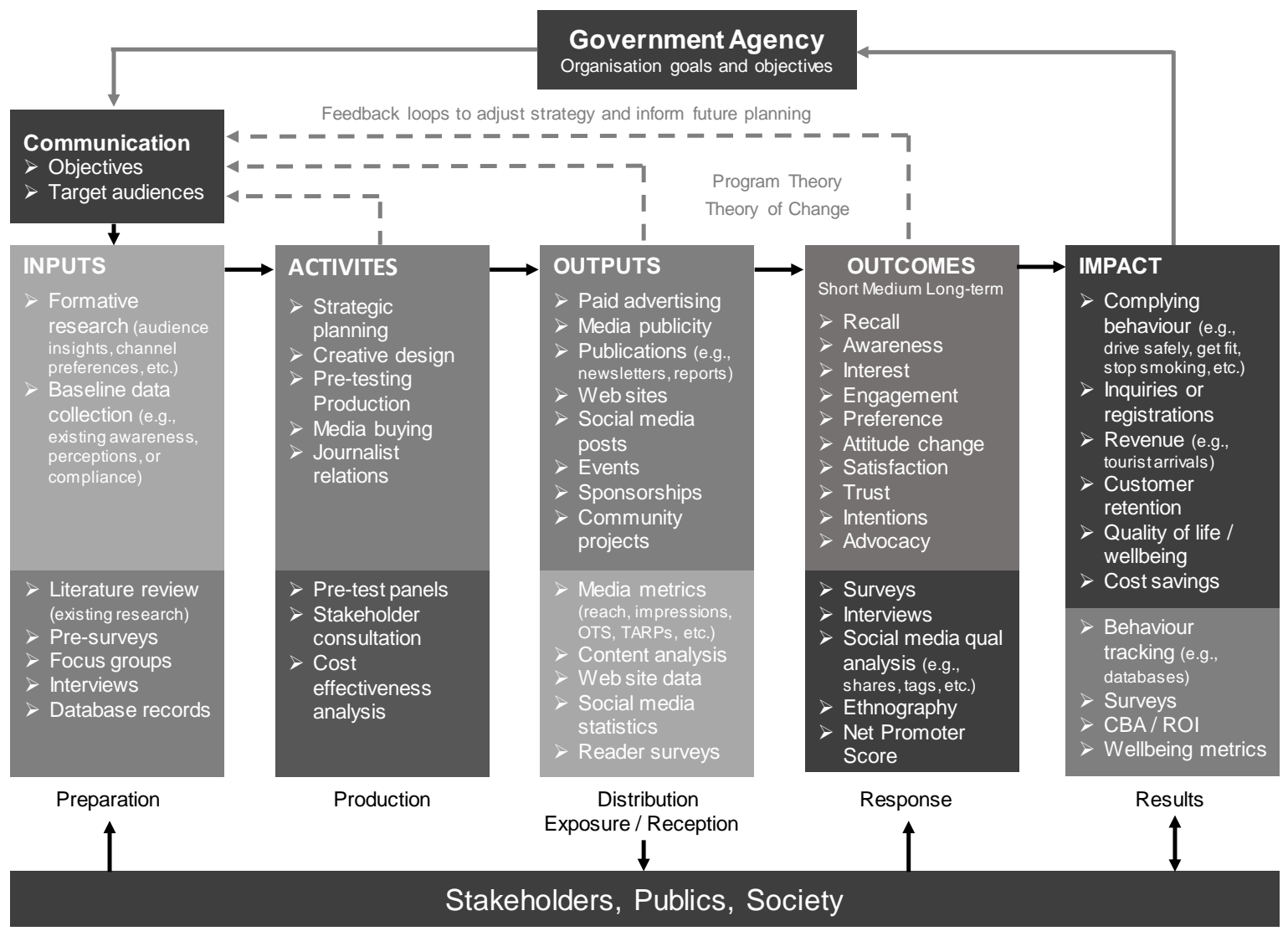


In addition to these clarifications, another subtle but important feature of the DPC model is that, in addition to showing a direct connection between impact and the relevant government agency, it shows that the 'inputs' stage is informed by stakeholders, publics and the interests of society as well as the organization, as illustrated by the arrows (see Figure 4). For example, stakeholder and public attitudes, perceptions, needs, and channel preferences as well as societal interests should inform communication strategy. Furthermore, in addition to information and consideration flowing from external parties as well as the organization at the 'inputs' stage, the model highlights that, while 'outputs' flow outwards from the organization, evaluation of 'outcomes' requires assessment of response from stakeholders, publics and society to the organization, and impact is bi-directional. That is to say, impact on the organization as well as impact on stakeholders, publics, and society should be evaluated.

This model represents a significant advance over traditional and even other contemporary models of evaluation for strategic communication because of its incorporation of two-way communication, dialogue, and engagement as well as concepts such as corporate responsibility towards publics and society. Other models are shown to be organization-centric.

However, even this model can be shown to lack some key elements and considerations, and the DPC (2017) model was undergoing further development at the time of this research. Critical analysis reveals four key gaps in this model and in evaluation theory for strategic communication generally relevant to RQ 2 and RQ 3 as follows.

1. Even though this model recognizes stakeholders, publics and society and seeks input from them as well as the organization in planning public communication, the model shows that communication objectives are already determined prior to formative research. This means that communication objectives could be unrealistic or even in conflict with stakeholders and publics.

2. Like all program logic models, the stages are shown as separate 'boxes' when, in reality, they overlap and are interconnected. For example, journalist relations and production such as events and Web content continue throughout a program or campaign. Also, the boxes imply a linear progression when, in fact, they are contingent on a number of factors. Feedback (illustrated in all the models examined) may indicate a need for adjustment of strategy informing an iterative rather than a linear process.

3. A major omission from all the models examined is that they do not recognize or suggest evaluation of context. Both internal and external context has a major impact on whether or not strategic communication is effective. For example, internal context includes resources such as staff, budget, management decisions, product or service, quality, and so on. External context includes economic, political, social, cultural, and competitive factors. For example, in addition to macro-societal, political, and economic shifts such as the UK voting to leave the European Union (Brexit), the election of Donald Trump as president of the USA, and economic recession in a number of European countries exacerbated by the arrival of unprecedented numbers of refugees, factors such as a competitor launching a new low-cost service, a new entrant to a market, or an unexpected crisis or scandal can radically affect a strategic communication program.

4. Even though the DPC model recognizes the need to evaluate impact on stakeholders, publics and society as well as the organization, it and all other models focus only on intended impact - i.e., what the organization wants to achieve. This and other models do not recognize, and therefore do not evaluate, unintended impact. By only evaluating outcomes and impact that the organization intends to create, evaluation can miss important 
reactions and responses and, accordingly, does not fully inform an organization. For example, an organization may succeed in selling its products or services or gaining approval for a development, but it might cause resentment among communities leading to longer-term opposition or reputation or brand damage.

\section{The Public Health England evaluation model}

The first evaluation model found to recognize context is that of Public Health England, an executive agency of the UK Department of Health responsible for planning and conducting health education and promotion campaigns across the UK. The PHE model of evaluation (Public Health England, 2017) takes its design from the 'sales funnel', which in turn is based on the AIDA model of persuasion applied in advertising (Strong, 1925) and its various derivatives that explain a 'customer journey' from awareness to interest, desire, and then action. Like 'sales funnel' models, the PHE evaluation model represents the process of a campaign as a triangle that narrows from a wide range of inputs, information, and potential customers at its base (usually shown at the top) to progressively smaller numbers at the outcomes and impact stages. (See Figure 5.)

This model is a further step forward in its recognition of context and its explicit recognition that numbers decline as communication progresses through the steps identified by $\mathrm{W}$. J. McGuire (1985, 2013) from audience exposure to attention, awareness, acceptance, retention, attitude change, action or behaviour change, and sometimes to advocacy (what McGuire calls 'proselytizing'). The narrowing triangle symbolizes a reality that the equal size boxes in typical program logic models fail to reflect. However, the PHE model is light on detail and some stages are poorly explained, such as inputs which are described only as "costs of the campaign, time and resources” (see Figure 5).

Figure 5. The Public Health England (2017) evaluation model.

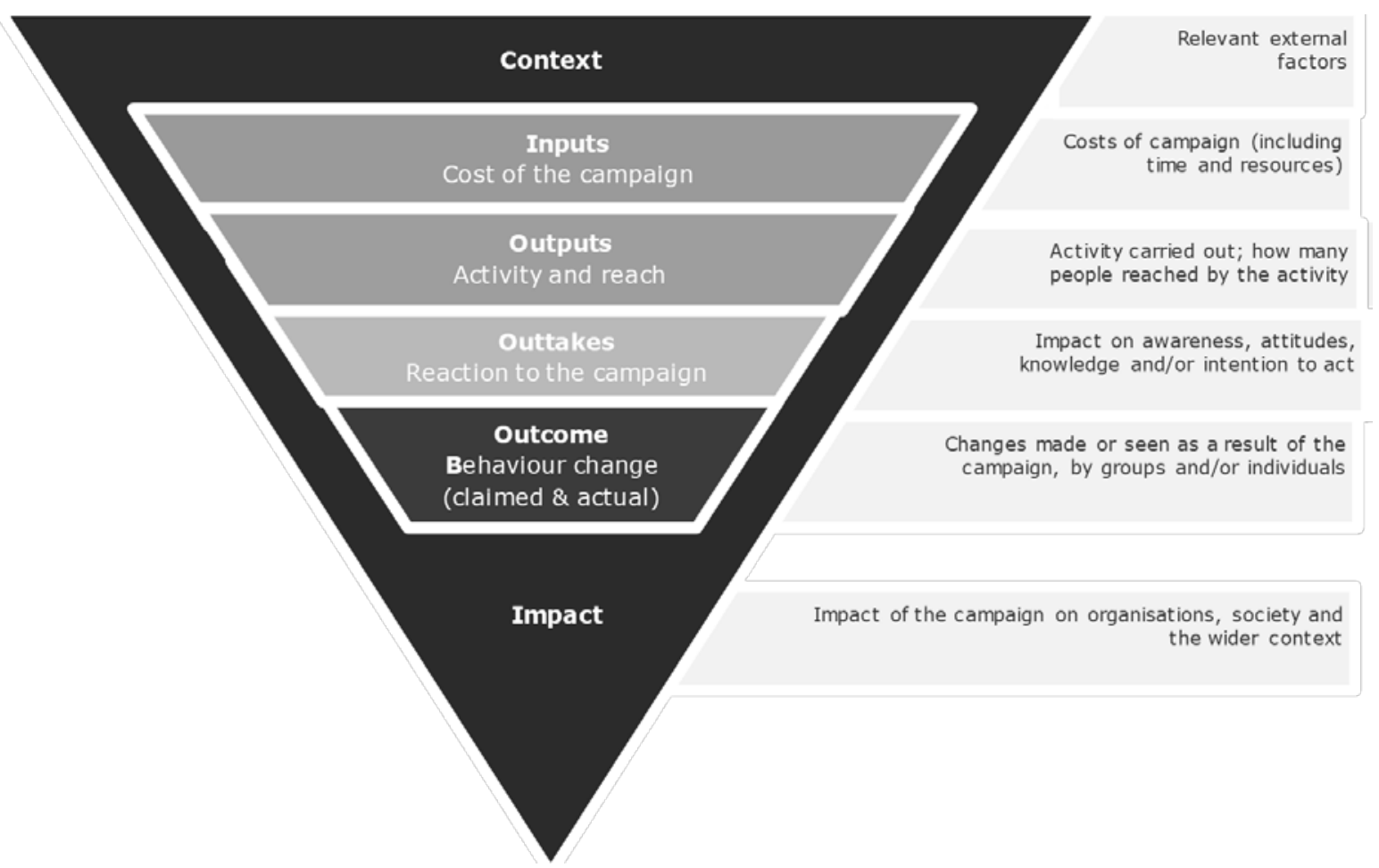




\section{An integrated evaluation model}

This analysis suggests directions for further development of evaluation models for strategic communication. In response to RQ 4, Figure 6 and following discussion attempts to bring together learning from this research in an expanded integrated evaluation model for strategic communication - that is, one that integrates the best features and some missing features from other models and also integrates an organization with its stakeholders, publics and society rather than present a top-down, one-way flow of information and effects. This model was developed collaboratively with the Public Relations Institute of Australia, which has published a modified version in its evaluation guidelines for members (PRIA, 2017).

Figure 6. An integrated model of evaluation for strategic communication (Macnamara, 2018).

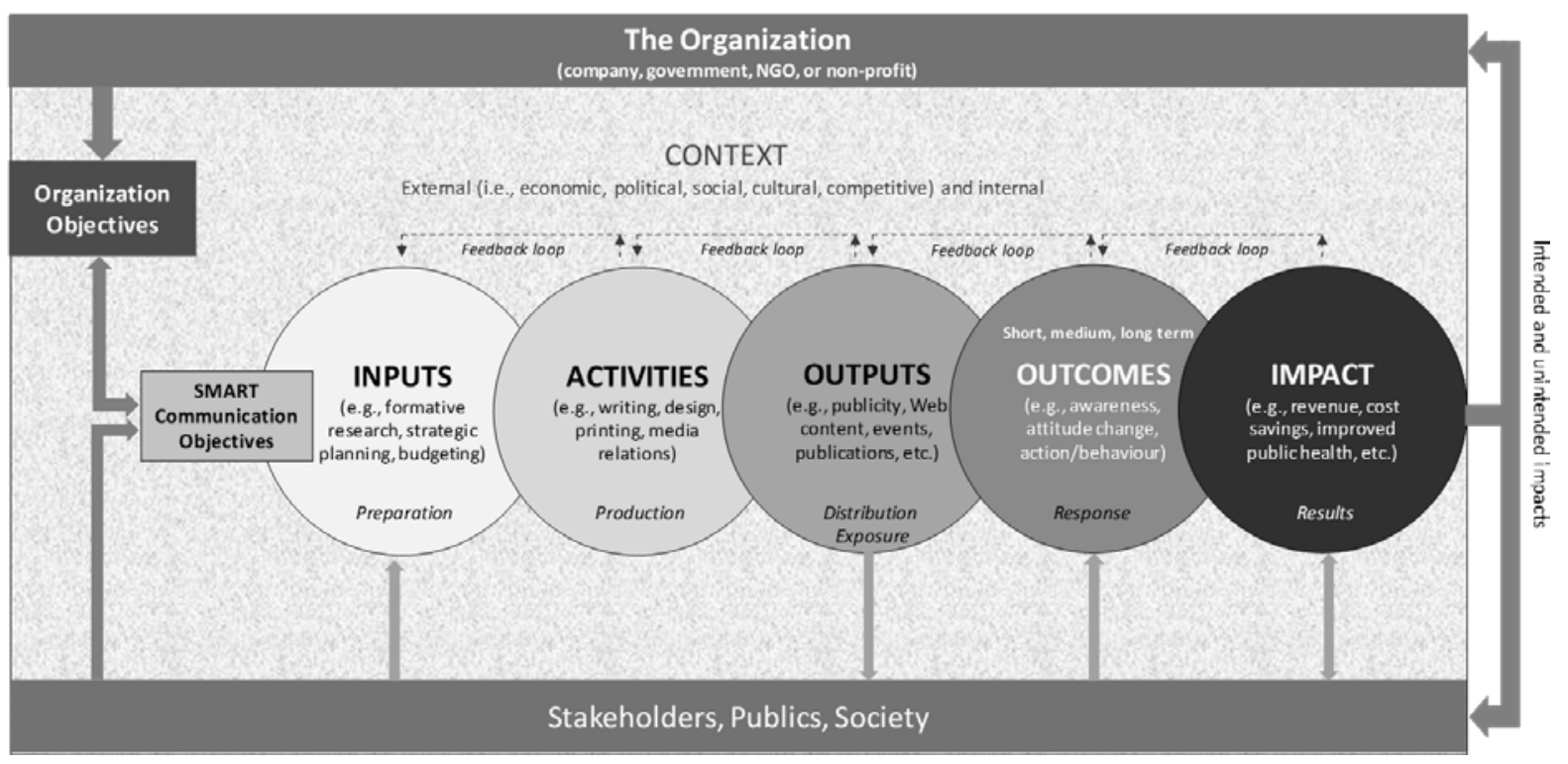

The integrated model presented in Figure 6 addresses the four gaps identified in existing models of evaluation as well as highlighting the two-way nature of communication and interaction with stakeholders, publics and society. Its specific features include the following.

- It shifts communication objectives from being a pre-determined antecedent to the communication program set unilaterally by the organization to being the result of (a) internal planning to achieve the organization's objectives and (b) consideration of the views, needs, and interests of stakeholders, publics and society. It proposes that setting communication objectives should be informed by research as well as the organization and notes that these should be SMART (specific, measurable, achievable, relevant, and timebound).

- It recognizes that inputs, activities, outputs, outcomes, and impact are overlapping stages in a program and are contingent rather than a simple linear progression.

- It shows the ongoing iterative two-way nature of interaction between an organization and its stakeholders and publics and society generally, as represented in the arrows below each stage. Inputs flow into the organization, such as formative research as well as from the organization (e.g., budget and resources); outputs flow out from the organization to stakeholders, publics and society; outcomes are evaluated by responses and reactions from stakeholders, publics and society to the organization; and impact occurs in both directions. 
- All stages of strategic public communication are conducted within contexts and the internal and external context should be monitored and evaluated throughout, making adjustments to strategy if required.

- Unintended as well as intended impacts should be evaluated.

\section{Discussions and conclusions}

The findings of this study reveal considerable progress in the application of theory of change, program theory, and its implementation through program logic models in the field of strategic communication. In addition, this study draws attention to a number of continuing gaps and proposes how these might be addressed to further overcome 'stasis' in the field. Thus, this study offers a contribution to evaluation theory for strategic communication.

The models examined and the findings of this study were the result of collaboration between communication practitioners and academics, rather than being developed in practice or the academy alone. This should be welcomed and adopted as an approach for further research in this area, as it overcomes the argument that academic models are too theoretical and the pitfall that many previous models developed in industry failed to adequately apply social science research methodology. This collaborative approach is a second useful outcome of the research.

Beyond informing and guiding processes of evaluation, evaluation models also can make a larger contribution to the theory and practice of strategic communication - a field characterized by considerable debate as evidenced in two International Communication Association (ICA) pre-conferences (2011 and 2017) and many articles in this journal and elsewhere. Evaluation models not only serve to overview and guide the steps in evaluation of strategic public communication; they also identify the intent and underlying logic of strategic communication. Pawson and Tilley (1997, 2001), who developed what is called 'realist evaluation', say that evaluation identifies "what works in which circumstances and for whom?" rather than merely "does it work?" (as cited in Better Evaluation 2016, para. 2). In simple terms, evaluation models reveal what is intended to be done to whom and whose interests are served. Thus, evaluation models reveal how strategic communication is theorized as well as how it is operationalized. Therefore, evaluation models that identify formative (i.e., planning), process, and summative evaluation are an ideal observation point from which to observe the real but often disguised or hidden motives and intentions that shape the field as well as the full range of effects. In that sense, this analysis and its illumination of the organization-centricity that is embedded in the planning and evaluation of strategic communication and the one-way focus of much strategic communication management provides food for thought in relation to strategic communication theory and practice. As Tom Peters noted, what gets measured is what gets done (Peters, $1986)^{4}$.

\section{References}

AMEC (Association for Measurement and Evaluation of Communication). (2010). Barcelona Declaration of Measurement Principles. London, UK: Author. Retrieved from http://amecorg.com/2012/06/barcelona-declaration-of-measurement-principles

AMEC (Association for Measurement and Evaluation of Communication). (2015). Barcelona principles 2.0. London, UK: Author. Retrieved from http://amecorg.com/barcelona-principles-2-0 AMEC (Association for Measurement and Evaluation of Communication). (2017). AMEC integrated evaluation framework. London, UK: Author. Retrieved from https://amecorg.com/amecframework 
Anderson, A. (2005). The community builder's approach to theory of change: A practical guide to theory and development. New York, NY: The Aspen Institute Roundtable on Community Change.

Bartholomew, D. (2016). Metrics man: It doesn't count unless you can count (Z. Chen, Ed.). New York, NY: Business Expert Press.

Bauman, A., \& Nutbeam, D. (2014). Evaluation in a nutshell: A practical guide to the evaluation of health promotion programs (2nd ed.). North Ryde, NSW: McGraw-Hill.

Better Evaluation. (2016). Realist evaluation [Web site]. Melbourne, Vic: Author. Retrieved from http://betterevaluation.org/approach/realist_evaluation

Bickman, L. (1990). Using program theory to describe and measure program quality. New Directions for Evaluation, 47, 61-72.

Broom, G. (2009). Cutlip \& Center's effective public relations (10th ed.). Upper Saddle River, NJ: Pearson.

Chen, H., \& Rossi, P. (1983). Evaluating with sense: The theory-driven approach. Evaluation Review, 7(3), 283-302. doi.org/10.1177/0193841X8300700301

Clark, H. (2004). Deciding the scope of a theory of change. New York, NY: ActKnowledge.

Clark, H., \& Taplin, D. (2012). Theory of change basics: A primer on theory of change. New York, NY: Actknowledge.

DPC (Department of Premier and Cabinet). (2017). New South Wales government evaluation framework for advertising and communication. Sydney, NSW: Author.

E-marketer. (2016, April 21). Worldwide ad spending growth revised downward [Web site]. Retrieved from http://www.emarketer.com/Article/Worldwide-Ad-Spending-Growth-RevisedDownward/1013858

European Commission. (2015a). Better regulation guidelines. Brussels, Belgium: Author. Retrieved from http://ec.europa.eu/smart-regulation/guidelines/toc_guide_en.htm

European Commission. (2015b). Toolkit for the evaluation of communication activities. Brussels, Belgium: Author. Retrieved from

http://ec.europa.eu/dgs/communication/about/evaluation/documents/communication-evaluationtoolkit_en.pdf

European Commission. (2015c). External communication network code of conduct on measurement and evaluation of communication activities. Brussels, Belgium: Author.

European Commission. (2015d, November 17). Synergies and efficiencies review: Report from the Working Group on External and Internal Communication. Brussels, Belgium: Author.

Fairchild, M. (1997). How to get Real value from public relations. London, UK: ICO.

Funnell, S., \& Rogers, P. (2011). Purposeful program theory: Effective use of theory of change and logic models. San Francisco, CA: Jossey-Bass.

GCS (Government Communication Service). (2016). Evaluation framework. London, UK: Cabinet Office, HM Government. Retrieved from https://gcs.civilservice.gov.uk/guidance/evaluation/toolsand-resources

Geertz, C. (1973). Thick description: Toward an interpretive theory of culture. In The interpretation of cultures: Selected essays (pp. 3-30). New York, NY: Basic Books.

Gregory, A., \& Watson, T. (2008). Defining the gap between research and practice in public relations programme evaluation: Towards a new research agenda. Journal of Marketing Communications, 24(5), 337-350. doi.org/10.1080/13527260701869098

Greenwood, D., \& Levin, M. (2006). Introduction to action research: Social research for social change. Thousand Oaks, CA: Sage.

Grunig, J. (2008). Conceptualizing quantitative research in public relations. In B. van Ruler, A. Verčič, \& D. Verčič (Eds.), Public relations metrics, research and evaluation (pp. 88-119). New York, NY: Routledge.

Grunig, L., Grunig J., \& Dozier, D. (2002). Excellent organizations and effective organizations: A study of communication management in three countries. Mahwah, NJ: Lawrence Erlbaum.

Henert, E., \& Taylor-Power, E. (2008). Developing a logic model: Teaching and training guide. Madison, WI: University of Wisconsin-Extension Program. Retrieved from https://fyi.uwex.edu/programdevelopment/files/2016/03/Imguidecomplete.pdf 
Huhn, J., Sass, J., \& Storck, C. (2011). Communication controlling: How to maximize and demonstrate the value creation through communication. Berlin, Germany: German Public Relations Association (DPRG). Retrieved from http://www.communicationcontrolling.de/fileadmin/communicationcontrolling/sonst_files/Position _paper_DPRG_ICV_2011_english.pdf

IPA (Institute of Practitioners in Advertising). (2016a). The IPA is widely recognised as the world's most influential professional body for practitioners in advertising and marketing communications [Web site]. London, UK: Author. Retrieved from http://www.ipa.co.uk/about

Kellogg Foundation. (1998/2004). Logic model development guide. Battle Creek, MI: Author. Retrieved from http://www.epa.gov/evaluate/pdf/eval-guides/logic-model-development-guide.pdf

Kindon, S., Pain, R., \& Kesby, M. (Eds.). (2007). Participatory action research approaches and methods: Connecting people, participation and places. Abingdon, UK: Routledge.

Knowlton, L. \& Phillips, C. (2013). The logic model guidebook: Better strategies for great results (2nd ed.). Thousand Oaks, CA: Sage.

Lewin, K. (1946). Action research and minority problems. Journal of Social Issues, 2(4), 34-46.

Likely, F., \& Watson, T. (2013). Measuring the edifice: Public relations measurement and evaluation practice over the course of 40 years. In J. Sriramesh, A. Zerfass, \& J. Kim (Eds.), Public relations and communication management: Current trends and emerging topics (pp. 143-162). New York, NY: Routledge.

Lindenmann, W. (1997/2003). Guidelines for measuring the effectiveness of PR programs and activities. Gainesville, FL: Institute for Public Relations. Retrieved from http://www.instituteforpr.org/wp-content/uploads/2002_MeasuringPrograms.pdf

Macnamara, J. (2015). Overcoming the measurement and evaluation deadlock: A new approach and model. Journal of Communication Management, 19(4), 371-387. doi: 10.1108/JCOM-04-20140020

Macnamara, J. (2018). Evaluating public communication: New models, standards, and best practice. Abindgon, UK: Routledge.

Macnamara, J., \& Likely, F. (2017). Revisiting the disciplinary home of evaluation: New perspectives to inform PR evaluation standards. Research Journal of the Institute for Public Relations, 2(2), 121.

Macnamara, J., Lwin, M., Adi, A., \& Zerfass, A. (2016). 'PESO' media strategy shifts to 'SOEP’: Opportunities and ethical dilemas. Public Relations Review, 42(3), 377-385. doi: 10.1016/j.pubrev.03.001

Macnamara J., \& Zerfass, A. (2017). Evaluation stasis continues in PR and corporate communication: Asia Pacific insights into causes. Communication Research and Practice. doi.org/10.1080/22041451.2017.1275258

McGuire, W. (1985). Attitudes and attitude change. In G. Lindzey \& E. Aronson (Eds.), Handbook of social psychology, Vol. 2 (3rd ed., pp. 233-346). New York, NY: Random House.

McGuire W. (2013). McGuire's classic input-output framework for constructing persuasive messages. In R. Rice \& C. Atkin (Eds.), Public communication campaigns (4th ed., pp. 133-145). Thousand Oaks, CA: Sage. (Original work published 1989)

Milstein, B., \& Chapel, T. (2014). Developing a logic model or theory of change. Community Tool Box. Lawrence, KS: University of Kansas Work Group for Community Health and Development. Retrieved from http://ctb.ku.edu/en/table-of-contents/overview/models-for-community-health-anddevelopment/logic-model-development/main

Patel, S. (2015, May 13). Why you should ignore vanity metrics and focus on engagement. Forbes. Retrieved from http://www.forbes.com/sites/sujanpatel/2015/05/13/why-you-should-ignore-vanitymetrics-focus-on-engagement-metrics-instead/\#59ea320a574e

Pawson, R., \& Tilley, N. (1997). Realistic evaluation. London, UK: Sage.

Pawson, R., \& Tilley, N. (2001). Realistic evaluation bloodlines. American Journal of Evaluation, 22, 317-324.

Peters, T. (1986). What gets measured gets done. Tom Peters' Writing [Web log]. Retrieved from http://tompeters.com/columns/what-gets-measured-gets-done

Peters, T., \& Waterman, R. (1982). In search of excellence: Lessons from America's best-run companies. New York, NY: Harper Collins. 
PRIA (Public Relations Institute of Australia). (2017). Measurement and evaluation framework. Sydney, NSW: Author. Retrieved from https://www.pria.com.au/resources/measurementevaluation

Public Health England. (2017). Evaluation model. London, UK: Author.

Rossi, P., Lipsey, M., \& Freeman, H. (2004). Evaluation: A systematic approach (7th ed.). Thousand Oaks, CA: Sage.

Strong, E. (1925). Theories of selling. Journal of Applied Psychology, 9(1), 75-86.

Tedlock, B. (2008). The observation of participation and the emergence of public ethnography. In N. Denzin \& Y. Lincoln (Eds.) Strategies of qualitative inquiry (3rd ed., pp. 151-171). Thousand Oaks, CA: Sage.

Tench, R., Verčič, D., Zerfass, A., Moreno, A., \& Verhoeven, P. (2017). Communication excellence: How to develop, manage and lead exceptional communications. London, UK: Palgrave Macmillan.

Thomas, J. (2008). Advertising effectiveness. Decision Analyst [Web site]. Retrieved from http://www.decisionanalyst.com/publ_art/adeffectiveness.dai

USC (University of Southern California, Annenberg Center for Public Relations) \& The Holmes Report. (2016). Global Communications Report 2016. Retrieved from www.holmesreport.com/docs/default-source/default-document-library/2016-globalcommunications-report.pdf?sfvrsn=2

Watson, T. (2012). The evolution of public relations measurement and evaluation. Public Relations Review, 38(3), 390-398.

Watson, T., \& Noble, P. (2014). Evaluating public relations: A best practice guide to public relations planning, research and evaluation (3rd ed.). London, UK: Kogan Page.

Weiss, C. (1972). Evaluative research: Methods of assessing program effectiveness. Englewood Cliffs, NJ: Prentice Hall.

Wholey, J. (1979). Evaluation: Promise and performance. Washington, DC: Urban Institute Press.

Wholey, J. (1983). Evaluation and effective public management. Boston, MA: Little Brown \& Co.

Wholey, J. (1987). Evaluability assessment: Developing program theory. New Directions for Program Evaluation, 33, 77-92. doi.org/10.1002/ev.1447

Wholey, J., Hatry, H., \& Newcomer, K. (Eds.). (2010). Handbook of practical program evaluation (3rd ed.). San Francisco, CA: Jossey-Bass.

Zerfass, A. (2010). Assuring rationality and transparency in corporate communications. Theoretical foundations and empirical findings on communication controlling and communication performance management. In M. Dodd \& K. Yamamura (Eds.), Ethical issues for public relations practice in a multicultural world, $13^{\text {th }}$ International Public Relations Research Conference (pp. 947-966). Gainesville, FL: Institute for Public Relations. Retrieved from http://iprrc.org/paperinfo_proceedings

Zerfass, A., Verčič, D., Verhoeven, P., Moreno, A., \& Tench, R. (2012). European communication monitor 2012: Challenges and competencies for strategic communication. Brussels, Belgium: European Association of Communication Directors (EACD), European Public Relations Education and Research Association (EUPRERA), and Helios Media.

Zerfass, A., Verčič, D., Verhoeven, P., Moreno, A., \& Tench, R. (2015). European communication monitor 2015. Brussels, Belgium: European Association for Communication Directors (EACD) and European Public Relations Education and Research Association (EUPRERA) in association with Helios Media, Berlin. Retrieved from_http://www.zerfass.de/ECMWEBSITE/media/ECM2015-Results-ChartVersion.pdf

Zerfass, A., \& Volk, S. (2017, in print). Aligning and linking communication with organizational goals. In V. Luoma-aho \& M. Canel (Eds.), Handbook of public sector communication. London, UK: Wiley-Blackwell.

1 There is an extensive body of literature on evaluation based on theory of change such as the work of Anderson (2005), Clark (2004), Clark and Taplin (2012), Funnel and Rogers (2011) and Milstein and Chapel (2014) and program theory (e.g., Bickman, 1990; Funnel \& Rogers, 2011; Rossi, Lipsey, \& Freeman, 2004) that has built on the pioneering evaluation work of Carol Weiss (1972), Huey Chen and Peter Rossi (1983), and Joseph Wholey $(1979,1983,1987)$. 
2 The principles were adopted at the second European Summit on Measurement hosted by the International Association for Measurement and Evaluation of Communication (AMEC) in Barcelona by more than 200 delegates from 33 countries.

3 The participatory action research stage of this study involved a six-month attachment of the author to work within the UK Government Communication Service (GCS) and the UK Department of Health (1 July-23 December 2016) as well as serve as a member of the Evaluation Council of the UK GCS, and work with the other organizations participating in the research.

4 While this adage is often attributed to Tom Peters and used in his recent writing, in the popular book, In Search of Excellence written with Robert Waterman, the quote is attributed to organizational theorist Mason Haire (Peters \& Waterman 1982, p. 268).

\section{Citation:}

Macnamara, J. (2018, forthcoming). A review of new evaluation models for strategic communication: Progress and gaps. International Journal of Strategic Communication, 12(2), xxx -xxx.

* Jim Macnamara PhD, MA, FPRIA, FAMI, CPM, FAMEC is Professor of Public Communication at the University of Technology Sydney, a position he took up in 2007 after a 30-year professional career spanning journalism, public relations, and media research. He began investigating evaluation in 1992 and immediately prior to joining UTS he was the founder and CEO of the Asia Pacific office of global media analysis firm, CARMA International. He is the author of 16 books including Evaluating Public Communication: Exploring New Models, Standards, and Best Practice (Routledge, 2018). 